\title{
Temperature - dependent Apoptosis Detected in Hybrids between Nicotiana debneyi and N. tabacum Expressing Lethality
}

\author{
Wataru MARUBASHI* and Marimi KOBAYASHI \\ School of Agriculture, Ibaraki University, Ami, Ibaraki 300-0393, Japan \\ *Corresponding author E-mail address: marubasi@ipc.ibaraki.ac.jp \\ Received 5 July 2002; accepted 27 August 2002
}

\begin{abstract}
Interspecific hybrids of Nicotiana debneyi $\times N$. tabacum L, show hybrid lethality, which is one of the mechanisms for reproductive isolation. Apoptotic changes were detected in the cells of hybrid seedlings expressing lethality at $28^{\circ} \mathrm{C}$, but not at high temperature $\left(34^{\circ} \mathrm{C}\right.$ ) indicating lethality was suppressed. When hybrid seedlings cultured at $34^{\circ} \mathrm{C}$ were transferred to $28^{\circ} \mathrm{C}$, lethal symptoms appeared. Chromatin condensation and nuclear fragmentation were observed in leaf protoplasts isolated from hybrid seedlings expressing lethality. Agarose gel analysis of DNA extracted from leaves of hybrid seedlings revealed a specific ladder pattern, suggesting nucleosomal fragmentation. Nuclear fragmentation was correlated with lethal symptoms in hybrid seedlings, as confirmed by flow cytometry. These results were observed in hybrid seedlings transferred to $28^{\circ} \mathrm{C}$ from $34^{\circ} \mathrm{C}$ but not in hybrid seedlings maintained at $34^{\circ} \mathrm{C}$. This phenomenon suggests that apoptosis in hybrid seedlings from the cross $N$. debneyi $\times N$. tabacum is temperature dependent.
\end{abstract}

Key words: apoptosis, chromatin condensation, DNA fragmentation, hybrid lethality, Nicotiana, nuclear fragmentation, temperature

Hybrid lethality is a postzygotic mechanism for the reproductive isolation of species (Stebbins 1966). This phenomenon has been observed in interspecific hybrids of several genera, including crop plants (Oka 1962; Phillips and Reid 1975; Zeven 1981). Hybrid lethality is also a significant obstacle preventing wide hybridization in plant breeding programs.

In the genus Nicotiana, Yamada et al. (1999) performed hybridization of 186 cross combinations among 17 species and observed that the hybrids of 14 cross combinations died at the seedling stage. $N$. glutinosa $\times N$. repanda is one of those cross combinations and the seedlings of the cross were analyzed with respect to cell death. Marubashi et al. (1999) revealed apoptotic features in the cells of hybrid seedlings of $N$. glutinos $a \times N$. repanda and concluded that apoptotic cell death induced hybrid lethality. Yamada et al. (2000) reported that the cell death inducing hybrid lethality of $N$. suaveolens $\times$ $N$. tabacum was apoptosis and apoptotic changes were detected in the cells of hybrid seedlings at 28 ${ }^{\circ} \mathrm{C}$ but not under high temperature $\left(36{ }^{\circ} \mathrm{C}\right)$, when the lethality was suppressed.

Hybrid seedlings of $N$. debneyi $\times N$. tabacum showed hybrid lethality at the cotyledonary stage
(Yamada et al. 1999). We detected apoptotic changes of nucleus, cytoplasm and DNA in hybrid seedlings of $N$. debneyi $\times N$. tabacum at $28^{\circ} \mathrm{C}$ but not at high temperature $\left(34^{\circ} \mathrm{C}\right)$, when the lethality was suppressed (Marubashi and Kobayashi, 2002). In this study, we analyzed apoptotic changes of hybrid seedlings of $N$. debneyi $\times N$. tabacum that were transferred to $28^{\circ} \mathrm{C}$ from $34^{\circ} \mathrm{C}$, when the lethality was suppressed.

Flowers of Nicotiana debneyi Domin., emasculated before anthesis, were pollinated with fresh pollen of $N$. tabacum L. cv. Hicks-2 (seeds from Japan Tobacco Inc., Iwata, Japan). $F_{1}$ seeds were sown on half-strength MS medium (Murashige and Skoog, 1962) supplemented with $1 \%$ sucrose and $0.2 \%$ gelrite, $\mathrm{pH} 5.8$, and were cultured at $28^{\circ} \mathrm{C}$ under continuous illumination (ca. $3000 \mathrm{~lx}$ ) for germination. Under these conditions, hybrid seedlings expressed lethality. To suppress lethality, the seedlings were transferred to $34^{\circ} \mathrm{C}$ immediately after germination. The surviving seedlings ( $45 \mathrm{day}$ old hybrid seedlings) at $34^{\circ} \mathrm{C}$ were exposed to $28^{\circ} \mathrm{C}$ to induce lethality.

For detection of apoptotic changes of nuclei, protoplasts were isolated from the leaves of hybrid seedlings. The leaves were sectioned and treated 
with enzyme solution containing $2 \%$ Onozuka $\mathrm{R}$ 10 cellulase (Yakult Co., Japan), $0.2 \%$ Macerozyme R-10 (Yakult Co., Japan), 0.7 M mannitol, and 10 $\mathrm{mM} \mathrm{CaCl}_{2}, \mathrm{pH} 5.6$, at $60 \mathrm{rpm}$ for $3-4 \mathrm{~h}$ at $30^{\circ} \mathrm{C}$. The protoplasts were separated from cellular debris by using a $42-\mathrm{mm}$ nylon sieve, and after centrifugation for $5 \mathrm{~min}$ at $100 \mathrm{~g}$ (room temperature), the supernatant was discarded and the protoplast pellet was resuspended in $0.7 \mathrm{M}$ mannitol. The protoplasts, stained with $0.5 \% 4^{\prime}-6$-diamino-2-phenylindole dihydrochloride (DAPI), were observed under a fluorescence microscope (AX70; Olympus, Japan) using $U$ excitation $(330-385 \mathrm{~nm})$ and photographed by a cooled CCD camera (Quantix; Photometrics).

For detection of DNA fragmentation, genomic DNA was extracted from the leaves of hybrid seedlings using the modified CTAB method (LoSchavw et al., 2000). To detect DNA fragmentation, extracted DNA was separated on a $2 \%$ agarose gel and was visualized using SYBR Gold (Wako Chemical Co., Japan) and UV light.

For cytometric analysis, nuclei were isolated from leaves, stems and roots of hybrid seedlings by chopping them in ice-cold buffer (Michaelson et al., 1991) and filtering the macerated tissue through $70-$ and $20-\mathrm{mm}$ nylon sieves. The nuclei were collected from the filtrate by centrifugation for 5 min at $700 \mathrm{~g}$ and suspended in sheath fluid (FACSFlow; Becton Dickinson) supplemented with $5 \mathrm{~g}$ $\mathrm{ml}^{-1}$ propidium iodide (PI) and $10 \mathrm{mg} \mathrm{ml}^{-1}$ RNase and incubated for $15 \mathrm{~min}$ at $37^{\circ} \mathrm{C}$. The DNA contents of the isolated nuclei were analyzed by a flow cytometer (FACSCalibur; Becton Dickinson).

The hybrid seedlings from the cross $N$. debneyi $\times$ N. tabacum exhibited hybrid lethality at $28^{\circ} \mathrm{C}$
(Yamada et al., 1999; Kobayashi and Marubashi, 2001). When $F_{1}$ seeds were sown on MS medium and cultured at $28^{\circ} \mathrm{C}$, the seeds germinated normally but all the seedlings expressed lethality at the cotyledonary stage. The lethal symptoms shown by the seedlings at $28^{\circ} \mathrm{C}$ were browning of hypocotyls, roots and cotyledons. The hybrid seedlings transferred to $34^{\circ} \mathrm{C}$ immediately after germination at 28 ${ }^{\circ} \mathrm{C}$ did not express any lethal symptoms and grew normally. Fig. 1A shows a hybrid seedling cultured at $34^{\circ} \mathrm{C}$ for 45 days after germination. When 45 day-old hybrid seedlings cultured at $34^{\circ} \mathrm{C}$ were transferred to $28^{\circ} \mathrm{C}$, their growth stopped, their stems turned brown within a few days and their leaves turned yellow within a week (Fig. 1B, C). All of the leaves of hybrid seedlings cultured at 28 ${ }^{\circ} \mathrm{C}$ for 21 days turned yellow (Fig. 1D). All of the hybrid seedlings died by 40 days after exposure to the lower temperature (Fig. 1E).

Apoptotic changes of nuclei were detected in leaves of hybrid seedlings transferred to $28^{\circ} \mathrm{C}$ from $34^{\circ} \mathrm{C}$. Fig. 2 shows progressive changes of nuclear structures. Normal chromatin structure was observed in the protoplasts isolated from hybrid seedlings cultured at $34^{\circ} \mathrm{C}$, and not exposed to $28^{\circ} \mathrm{C}$ (Fig. 2A). Chromatin condensation was observed in the protoplasts isolated from hybrid seedlings cultured at 28 for 14 days (Fig. 2B). Nuclear fragmentation was observed in the protoplasts isolated from hybrid seedlings cultured at $28^{\circ} \mathrm{C}$ for 30 days (Fig. 2C). Electrophoresis of total DNA isolated from the leaves of hybrid seedlings cultured for 14 days at 28 ${ }^{\circ} \mathrm{C}$ expressing lethality showed a distinctive ladder pattern on the agarose gel after staining with SYBR Gold, suggesting nucleosomal fragmentation of DNA (Fig. 3 lane 2). Chromatin condensation,
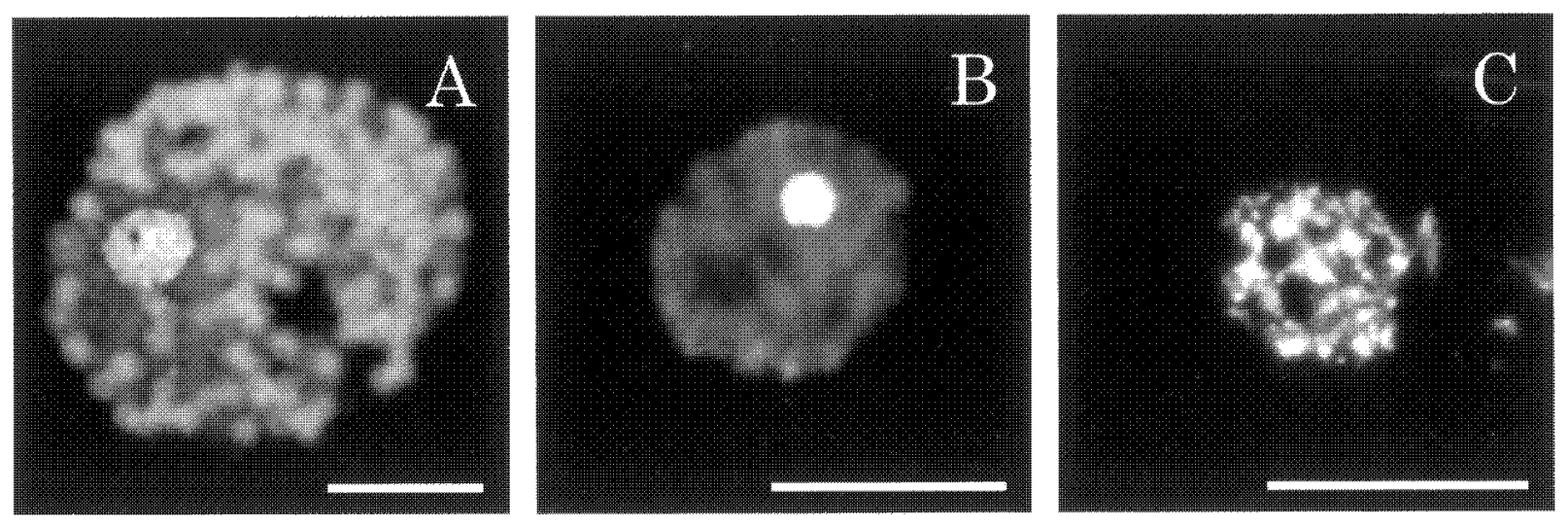

Fig. 2 Progressive changes of nuclear structure detected in protoplasts stained with DAPI. (A) Normal structure of chromatin in green leaves of a seedling cultured at $34^{\circ} \mathrm{C}$ for 45 days after germination. (B) Chromatin condensation in yellow leaves of a seedling cultured at $28^{\circ} \mathrm{C}$ for 14 days. (C) Nuclear fragmentation in yellow leaves of a seedling cultured at 28 ${ }^{\circ} \mathrm{C}$ for 30 days.

Bars are $5 \mu \mathrm{m}$. 

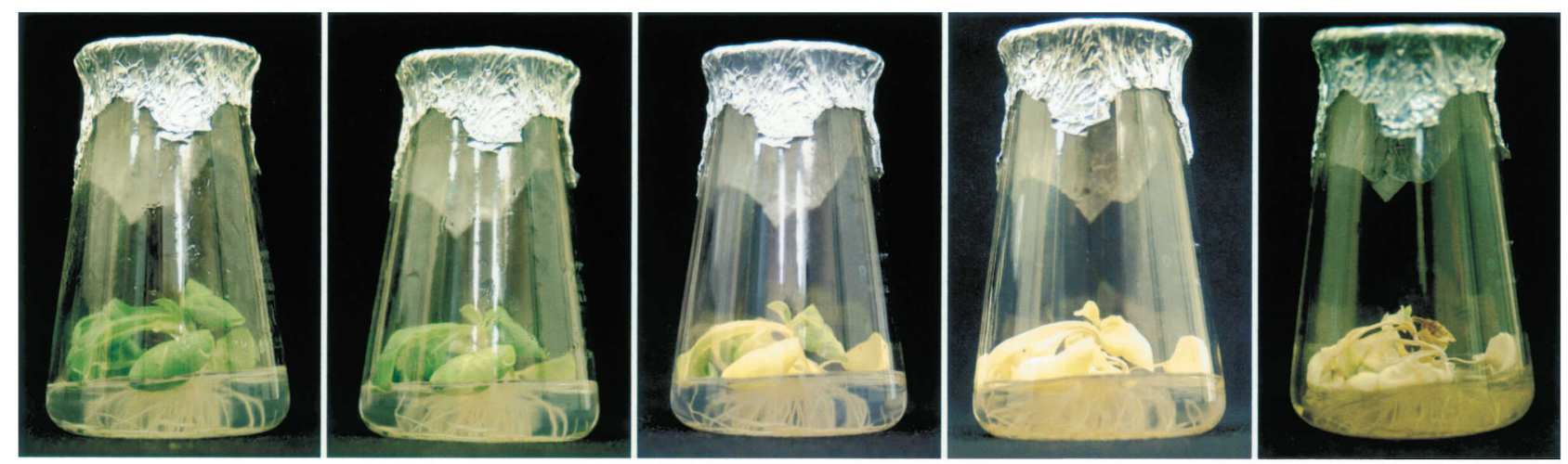

A

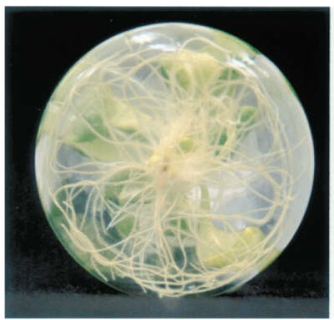

B
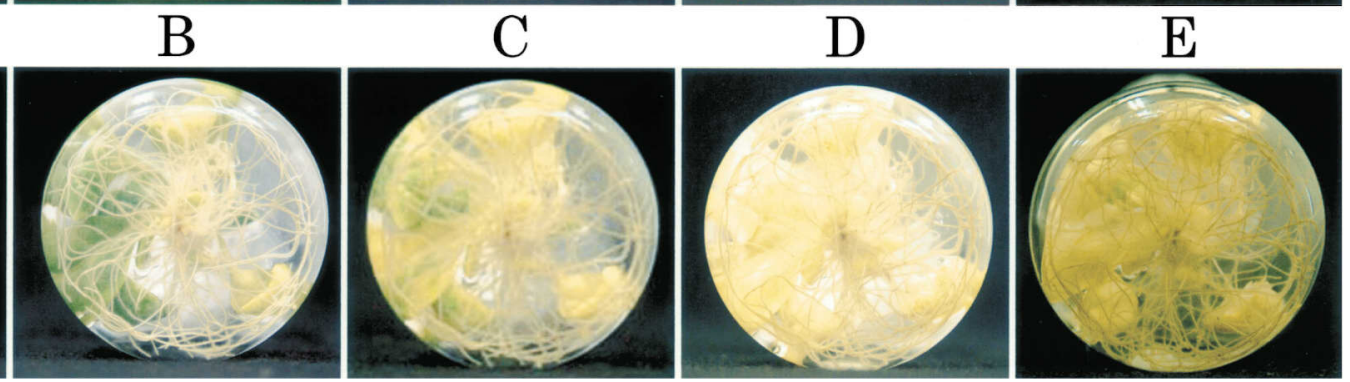

Fig. 1 Morphological changes of hybrid seedlings from the cross $N$. debneyi $\times N$. tabacum. (A) A seedling cultured at $34^{\circ}$ $\mathrm{C}$ for 45 days after germination grew without any lethal symptoms. (B) A seedling transferred to $28^{\circ} \mathrm{C}$ and cultured for 3 days stopped growth and the stem turned brown. (C) A seedling cultured at $28^{\circ} \mathrm{C}$ for 7 days showed chlorosis in some leaves. (D) A seedling cultured at $28^{\circ} \mathrm{C}$ for 21 days showed chlorosis in all the leaves. (E) A seedling cultured at $28^{\circ} \mathrm{C}$ for 40 days dried up and died.
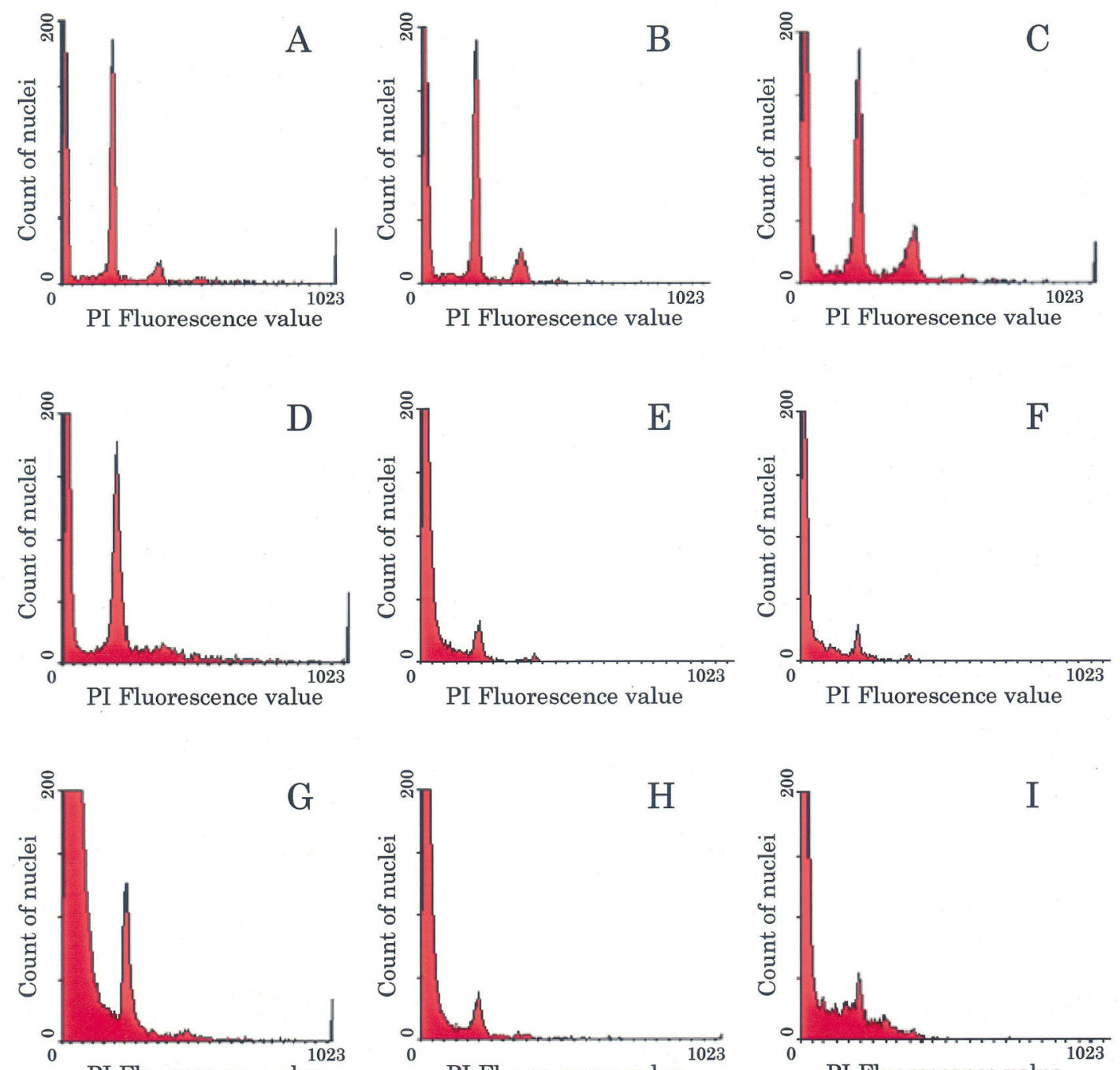

PI Fluorescence value

PI Fluorescence value

PI Fluorescence value

Fig. 4 Histograms indicating increased fragmentation of nuclei in leaves, stems and roots of hybrid seedlings. (A) - (C) A seedling cultured at $34^{\circ} \mathrm{C}$ for 45 days. (D) - (F) A seedling transferred to $28^{\circ}$ $\mathrm{C}$ and cultured for 14 days. (G) - (I) A seedling transferred to $28^{\circ} \mathrm{C}$ and cultured for 30 days. 


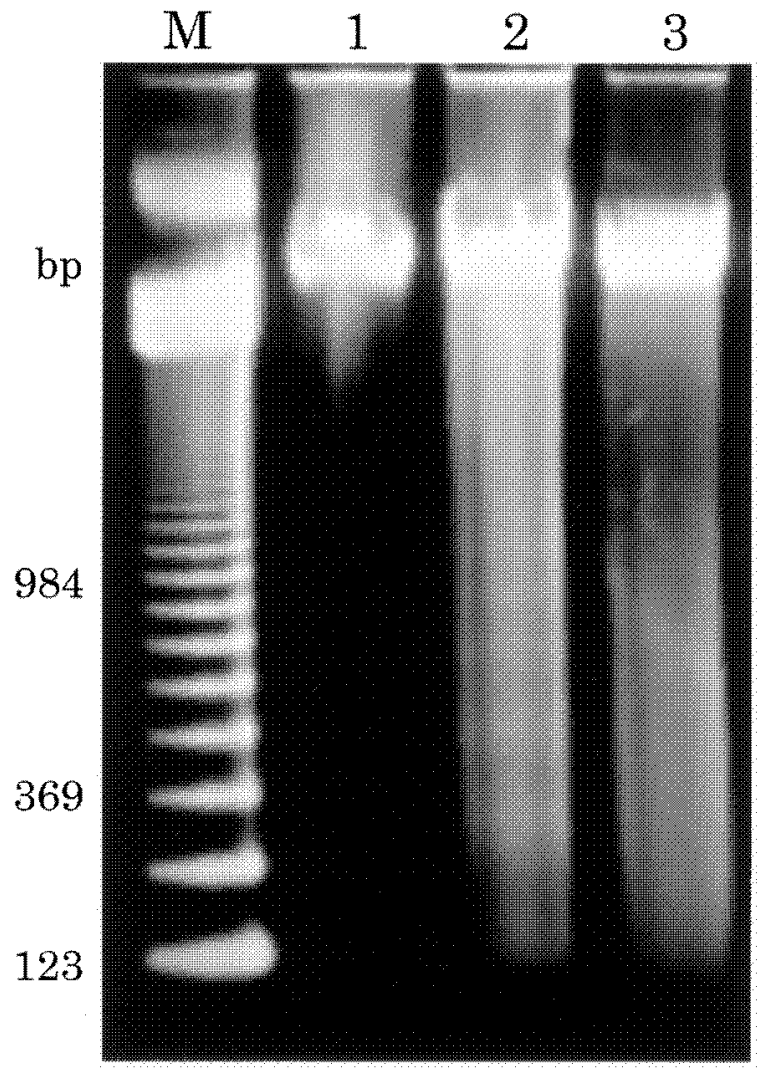

Fig. 3 DNA fragmentation detected in the leaves of hybrid seedlings. Lane 1, 123-bp DNA ladder markers; lane 2 , green leaves from a seedling cultured at $34{ }^{\circ} \mathrm{C}$ for 45 days; lane 3 , yellow leaves from a seedling transferred to $28^{\circ} \mathrm{C}$ and cultured for 14 days; lane 4 , yellow leaves from a seedling transferred to $28^{\circ} \mathrm{C}$ and cultured for 30 days.

nuclear fragmentation and DNA fragmentation are considered typical phenomena of apoptosis in animal cells (Kerr and Harmon, 1991). These results suggest that the cell death detected in hybrid seedlings from the cross $N$. debneyi $\times N$. tabacum exposed to $28^{\circ} \mathrm{C}$ is indeed apoptosis. Apoptosis in hybrid seedlings from the cross $N$. debneyi $\times N$. tabacum was temperature dependent because it was detected at $28^{\circ} \mathrm{C}$ but not at $34^{\circ} \mathrm{C}$.

Manabe et al. (1989) reported that hybrid lethality expressed in the cross $N$. suaveolens $\times N$. tabacum was suppressed at high temperature $\left(36^{\circ} \mathrm{C}\right)$ and the hybrid seedlings showed browning of stems and veins within $24 \mathrm{~h}$ when they were transferred to 28 ${ }^{\circ} \mathrm{C}$. In the same cross, Yamada et al. (2000) clarified that apoptotic cell death induced temperature--sensitive lethality in the hybrid seedlings. Marubashi et al. (1999) reported that apoptotic cell death induced lethality in hybrid seedlings from the cross $N$. glutinosa $\times N$. repanda and Yamada et al. (2001) showed that high temperature $\left(32^{\circ} \mathrm{C}\right)$ suppressed lethal symptoms in the same cross. In this study, we detected a new cross, $N$. debneyi $\times N$. tabacum, that showed temperature-dependent apoptosis in the hybrid seedlings. Temperature- dependent hybrid lethality in the genus Nicotina generally might be caused by apoptosis.

The nuclear fragmentation was further evaluated by analysis of DNA contents of nuclei isolated from the hybrid leaves, stems and roots using a flow cytometer. In the histograms of PI fluorescence values, indicating the relative mass of nuclear DNA, the hybrid seedlings with green leaves, green stems and white roots maintained at $34^{\circ} \mathrm{C}$ showed two peaks that might correspond to nuclei at the $G_{1}$ and $\mathrm{G}_{2} \mathrm{M}$ phases of the cell cycle (Fig. $\mathbf{4 A}-\mathrm{C}$ ). The hybrid seedlings cultured at $28^{\circ} \mathrm{C}$ for one week showed lethal symptoms. The leaves turned yellow and exhibited a smaller $G_{2} M$ peak (Fig. 4D). The stems and roots turned brown and exhibited a smaller $G_{1}$ peak, and additional peaks with lower fluorescence values appeared (Fig, 4E, F). These latter peaks, corresponding to fragmented nuclei, further increased in size in histograms of seedlings cultured at $28^{\circ} \mathrm{C}$ for 40 days (Fig. $\mathbf{G}$ ). These quantitative results support the conclusion that distinct nuclear fragmentation progressed with lethal symptoms.

\section{References}

Kerr, J. F. R., Harmon, B. V., 1991. Definition and incidence of apoptosis: an historical perspective. In: Tomei L.D. and F. O. Cope (Eds.): Apoptosis: the molecular basis of cell death, pp. 5-29. Cold Spring Harbor Laboratory Press, New York.

LoSchiavo, F., B., Baldan, D., Compaginin, R., Ganz, P., Mariani, Terzi, M., 2000. Spontaneous and induced apoptosis in embryogenic cell cultures carrot (Daucus carota L.) in different physiological states. Euro. J. Cell Biol., 79: 294-298.

Manabe, T., Marubashi, W., Onozawa, Y., 1989. Temperature-dependent conditional lethaloity in interspecific bybrids between Nicotiana suaveolens Lehm. and $N$. tabacum L. Proc. Of the 6 th International Congr. of SABRAO, $459-462$.

Marubashi, W., Yamada, T., Niwa, T., 1999. Apoptosis detected in hybrids between Nicotiana glutinosa $\times N$. repanda expressing lethality. Planta, 210: $168-171$.

Marubashi, W., Kobayashi, M., 2002. Apoptosis detected in hybrids between Nicotiana debneyi and N. tabacum. Ikushugaku Kenkyu, 4: in press (in Japanese).

Michaelson, M. J., Pris, H. J., Ellison, H. J., Johnston, J. S., 1991. Comparison of plant DNA contents determined by feulgen microspectrophtometry and laser flow cytometry. Am. J. Bot., 78: 183-188.

Murashige, T., Skoog, F., 1962. A revised medium for rapid growth and bioassays with tobacco tissue cultures. Physiol. Plant., 15: 473-497.

Oka, H. I., 1962. Phylogenetic differentiation of cultivated 
rice. $\mathrm{XX}$. Analysis of the genetic basis of hybrid breakdown in rice. Jpn. J. Genet., 37: 24-35.

Phillips, L. L., Reid, R. K., 1975. Interspecific incompatibility in Gossypium II. light and tumorigenesis in hybrids of G. klotzchianum. Am. J. Bot., 62: 790-796.

Stebbins, G.L., 1966. Reproducctive isolation and the origin of species. In: Processes of organic evolution. pp. 85 112, Prentice-Hall, New Jersey.

Yamada, T., Marubashi, W., Niwa, M., 1999. Detection of four lethality types in interspecific cross among Nicotiana spesies through the use of three rescue methods for lethality. Breeding Sci., 49: 203-210.

Yamada, T., Marubashi, W., Niwa, M., 2000. Apoptotic cell death induces temprature-sensitive lethality in hybrid seedlings and calli derived from the cross of Nicotiana suaveolens $\times N$. tabacum. Planta, 211: 614-622.

Yamada, T., Marubashi, W., Niwa, M., 2001. Psssible involvement of auxin-induced ethylene in an apoptotic cell death during temperature-- sensitive lethality expressed by hybrid between Nicotiana glutinosa and $N$. repanda. Plant Cell Physiol., 42: 923-930.

Zeven, A. C., 1981. Eighth sypplementary list of wheat varieties classified according to their genotype for hybrid necrosis. Euphytica, 30: $521-5$ 